\title{
Concurrent Validity of the 2005 Strong Interest Inventory: An Examination of Gender and Major Field of Study
}

\author{
Courtney E. Gasser \\ Lisa M. Larson \\ Fred H. Borgen \\ Iowa State University
}

This is the first article evaluating the concurrent validity of the 2005 Strong Interest Inventory (SII). The Basic Interest Scales (BISs) were substantially revised to reflect the changing workplace, so such an update is particularly important. Concurrent validity of the 41 content scales in the SII was examined for differentiating 31 college majors in a national college sample of 1,403 women and 469 men. Using discriminant analyses, three sets of content scales were used to predict major field of study. These were six General Occupational Scales, five Personal Style Scales, and 30 BISs. Each set of scales showed substantial concurrent validity in differentiating college major for women and men. The most specific scales, the BISs, were the most predictive of major, with hit rates 6 times greater than chance. Results clearly supported the concurrent validity and counseling utility of the content scales of the SII.

Keywords: Basic Interest Scales, concurrent validity, educational major, hit rates, 2005 Strong Interest Inventory

Vocational interests, measured for 80 years with the Strong Interest Inventories, are robust dimensions with stability over time and with potent implications for educational and career pursuits (Hansen, 2005; Harmon, Hansen, Borgen, \& Hammer, 1994; Low, Yoon, Roberts, \& Rounds, 2005). The 1994 Strong Interest Inventory (SII; Harmon et al., 1994; Strong, 1927) has recently been revised, and the newest version was released to the public in early 2005 (Donnay, Morris, Schaubhut, \& Thompson, 2005). Differences between the 1994 and 2005 SII include new occupational scales, the expansion of the Basic Interest Scales (BISs) from 25 to 30 scales, and the addition of a Teamwork scale to the Personal Style Scales (PSSs). The current study focuses on the concurrent

\footnotetext{
We would like to thank CPP, Incorporated for allowing us access to this rich data source. We would also like to especially thank David Donnay and Rich Thompson for their assistance in accessing the data.
}

JOURNAL OF CAREER ASSESSMENT, Vol. 15 No. 1, February 2007 23-43

DOI: $10.1177 / 1069072706294516$

(C) 2007 Sage Publications 
validity of the 41 content scales in the 2005 SII, and especially the new BISs, for differentiating college majors in a large national sample.

Vocational psychology researchers have used the SII to examine relations between interest and other constructs such as career choice (Toman \& Savickas, 1997), personality (Larson \& Borgen, 2002; Larson, Rottinghaus, \& Borgen, 2002; Staggs, Larson, \& Borgen, in press, 2004), ethnicity and culture (Davison Aviles \& Spokane, 1999; Fouad, 2002; Fouad, Harmon, \& Borgen, 1997; Lattimore \& Borgen, 1999), self-efficacy (Brown, Lent, \& Gore, 2000; Chartrand, Borgen, Betz, \& Donnay, 2002; Donnay \& Borgen, 1996; Luzzo \& Day, 1999), educational aspirations (Gasser, Larson, \& Borgen, 2004; Rottinghaus, Lindley, Green, \& Borgen, 2002), teaching development (Larkin, Harvey, \& Bechtel, 2002), satisfaction (Jackson, 2002; Zao, 2002;), academic or career progress (Barnes \& Herr, 1998; Kahn, Nauta, Gailbreath, Tipps, \& Chartrand, 2002), intelligence (Kaufman \& McLean, 1998), and theoretical applications (Betz \& Borgen, 2000; Borgen \& Harmon, 1996; Harmon \& Borgen, 1995).

The SII has also been used widely in practical applications such as career counseling (e.g., Buboltz, Thomas, \& Johnson, 2001; Hansen \& Campbell, 1985; Swanson \& Fouad, 1999; Zytowski \& Warman, 1982). In one study of career assessment practices, the SII was cited as the most frequently used interest measure by the sample of more than 600 counseling psychologists (Watkins, Campbell, \& Nieberding, 1994). Furthermore, this measure has been utilized in numerous case studies of vocational behavior (e.g., Prince, 1998; Savickas, 1998; Swanson, 1992).

Prior studies have examined the validity of the 1994 SII BISs (Donnay \& Borgen, 1996; Lattimore \& Borgen, 1999; Olsen, 1996; Ralston, Borgen, Rottinghaus, \& Donnay, 2004). However, this is the first article to examine indepth the incremental validity of the new 2005 BISs.

Specifically, the purpose of the current study was to provide concurrent criterion validity for the new SII primarily investigating the scales' abilities to differentiate between different college majors. This is important to provide evidence that the revised SII is valid and to provide guidance for practitioners transitioning to the new SII during the next few years. The 2005 SII has been revised to encompass a wider variety of BISs to account for the development of new interests in today's ever-changing workforce. Currently, the 2005 SII is a 291-item measure of vocational interests based on Holland's RIASEC model (Holland, 1997). Differences between the 1994 and 2005 SII include the expansion of the BISs from 25 to 30 scales, the inclusion of another PSS (the Teamwork scale), and a format change from a 3-point to 5-point differentiation of interest preference. These changes allow for the expression of new career options that have become available in the workforce in the past decade.

As part of the revision of the $2005 \mathrm{SII}$, the publisher, CPP Incorporated, sampled students taking college courses over the Internet as part of their revision and validation efforts. The authors were allowed access to this rich data set. Using discriminant analyses, we provide in this article initial concurrent criterion validity estimates of the 2005 SII for identifying students in a diverse array of majors. 
College major was the criterion variable, and the SII scales were the predictors. Three predictor sets of SII content scales were used for multivariate prediction of majors: 6 General Occupational Themes (GOTs), 30 BISs, and 5 PSSs.

We expected to find support for three hypotheses. First, although the PSSs and the PSSs and GOTs combined were expected to predict major field of study better than chance, it was expected that the inclusion of the BISs to the PSSs and GOTs would result in the highest level of prediction (cf. Donnay \& Borgen, 1996; Ralston et al., 2004; Ralston, Miller, Zakalik, Rottinghaus, \& Betz, 2003). Second, we expected that the strongest predictive set would be the $30 \mathrm{BISs}$ alone because of their greater number and specificity (cf. Donnay \& Borgen, 1996; Ralston et al., 2004; Ralston et al., 2003). Third, it was hypothesized that similar results would be found for men and women (Donnay \& Borgen, 1996; Olsen, 1996).

\section{METHOD}

\section{Participants}

A sample of exactly 1,873 participants was used as part of the 2005 SII revision data gathered by CPP, Incorporated. There were 1,403 women and 469 men in this national college sample. In regards to the disparate numbers of women and men, it appears that more women were conducting Internet searches on careerrelated topics during the time of the study. Also, given that participants needed to fill out a lengthy questionnaire of more than 300 items, it seems that women were more willing to do so and persist with the task than men. We hypothesize that this reflects national trends of higher percentages of women engaging in career-seeking behaviors. In regards to this being a national sample, the authors ran analyses on the zip codes of the sample's respondents, and found that the zip codes were widely distributed across the United States (see Table 1).

The age range of the sample was 17 to 57 years with a mean age of 22.61 $(\mathrm{SD}=5.86)$. The ethnicity of the sample was $73 \%$ White, $11 \%$ African American, 8\% Hispanic, $5 \%$ Asian, $3 \%$ other or multiple ethnicities. Participants were students endorsing one of 31 different majors as shown in Table 2. All participants endorsed that they were full-time students. The goal of the current education for the sample was undergraduate coursework or degrees (64.6\%), masters degrees (14.5\%), associates degrees (10\%), doctoral degrees $(4.9 \%)$, professional degrees (such as JDs and MDs; $4.5 \%)$, and trade school degrees (1.4\%).

\section{Procedures}

The sample was obtained through CPP, Incorporated. Participants were selected through a random sampling procedure as they clicked onto a certain Internet screen. Potential participants were those who entered career into the search engine. Every third person to enter that search word on the Google Web 
Table 1

Geographical Representation of the Total National Sample ( $N=1872$, with 47 missing zip codes)

\begin{tabular}{|c|c|c|c|}
\hline Area Defined by 1-Digit Zip & & State & $N$ \\
\hline \multirow[t]{8}{*}{ Northeast } & 0 & & 153 \\
\hline & 0 & Connecticut & 24 \\
\hline & 0 & Maine & 6 \\
\hline & 0 & Massachusetts & 49 \\
\hline & 0 & New Hampshire & 8 \\
\hline & 0 & New Jersey & 52 \\
\hline & 0 & Rhode Island & 10 \\
\hline & 0 & Vermont & 4 \\
\hline \multirow[t]{4}{*}{ Greater New York } & 1 & & 238 \\
\hline & 1 & Delaware & 5 \\
\hline & 1 & New York & 138 \\
\hline & 1 & Pennsylvania & 95 \\
\hline \multirow[t]{7}{*}{ Atlantic } & 2 & & 176 \\
\hline & 2 & District of Columbia & 2 \\
\hline & 2 & Maryland & 48 \\
\hline & 2 & North Carolina & 36 \\
\hline & 2 & South Carolina & 23 \\
\hline & 2 & Virginia & 54 \\
\hline & 2 & West Virginia & 13 \\
\hline \multirow[t]{6}{*}{ Southeast } & 3 & & 268 \\
\hline & 3 & Alabama & 40 \\
\hline & 3 & Florida & 121 \\
\hline & 3 & Georgia & 46 \\
\hline & 3 & Mississippi & 20 \\
\hline & 3 & Tennessee & 41 \\
\hline \multirow[t]{5}{*}{ Eastern Plains } & 4 & & 243 \\
\hline & 4 & Indiana & 95 \\
\hline & 4 & Kentucky & 26 \\
\hline & 4 & Michigan & 67 \\
\hline & 4 & Ohio & 55 \\
\hline \multirow[t]{7}{*}{ Northern Plains } & 5 & & 77 \\
\hline & 5 & Iowa & 14 \\
\hline & 5 & Minnesota & 29 \\
\hline & 5 & Montana & 2 \\
\hline & 5 & North Dakota & 6 \\
\hline & 5 & South Dakota & 3 \\
\hline & 5 & Wisconsin & 23 \\
\hline \multirow[t]{5}{*}{ Western Plains } & 6 & & 130 \\
\hline & 6 & Illinois & 67 \\
\hline & 6 & Kansas & 23 \\
\hline & 6 & Missouri & 28 \\
\hline & 6 & Nebraska & 12 \\
\hline \multirow[t]{3}{*}{ Southern Plains } & 7 & & 198 \\
\hline & 7 & Arkansas & 12 \\
\hline & 7 & Louisiana & 55 \\
\hline
\end{tabular}

(continued) 
Table 1 (continued)

\begin{tabular}{lllr}
\hline Area Defined by l-Digit Zip & & \multicolumn{1}{c}{ State } & $\boldsymbol{n}$ \\
\hline & 7 & Oklahoma & 20 \\
& 7 & Texas & 111 \\
Rocky Mountains & 8 & & 101 \\
& 8 & Arizona & 37 \\
& 8 & Colorado & 24 \\
& 8 & Idaho & 6 \\
& 8 & Nevada & 13 \\
& 8 & New Mexico & 5 \\
Pacific & 8 & Utah & 13 \\
& 8 & Wyoming & 2 \\
& 9 & & 242 \\
& 9 & Alaska & 6 \\
& 9 & California & 165 \\
Total & 9 & Hawaii & 11 \\
& 9 & Oregon & 21 \\
& 9 & Washington & 39 \\
& & & 1825 \\
\hline
\end{tabular}

page (www.google.com) was invited to take the 2005 SII for no charge. Google is a widely used Internet search engine. Human participants considerations were consistent with American Psychological Association (APA; 2002) guidelines, and involved informing the participants of what was expected and what would be the result of participating. Specifically, participants were informed in advance the number of items to be filled out, the time commitment, and the career report that would be received at the end of participation. No risks of participating were anticipated; however, the participants were told that they could discontinue the study at any time. In exchange for completing the 2005 SII, participants were given a brief summary of their results that included their six GOTs, estimated from the 1994 SII scoring keys.

\section{SII}

The SII comprises 291 items and was designed to capture an individual's career interests (Donnay et al., 2005). The revision of the 1994 SII resulted in some items being deleted, some items being slightly revised, and some new items being added. In short, there were 20 items with minor word changes, and 78 new items added to the 2005 SII (Donnay et al., 2005). Similar to the 1994 SII, the 2005 SII includes two sets of content scales, the 6 GOTs and the 30 BISs, and one set of empirically keyed scales, the 211 Occupational Scales (OSs). The OSs are not included in the current study and are not discussed. The 2005 SII was normed on a new reference group titled the General Representative Sample (GRS) that included 2,250 
Table 2

College Majors for the Female Sample $(n=1403)$ and for the Male Sample $(n=469)$

\begin{tabular}{|c|c|c|c|c|}
\hline College Major & Female $n$ 's & $\begin{array}{l}\text { \% of Female } \\
\text { Sample }\end{array}$ & Male $n$ 's & $\begin{array}{c}\% \text { of Male } \\
\text { Sample }\end{array}$ \\
\hline Accounting & 47 & 3.3 & 12 & 2.6 \\
\hline Administration & 38 & 2.7 & 17 & 3.6 \\
\hline Applied art \& design & 32 & 2.3 & 5 & 1.1 \\
\hline Architecture & 14 & 1.0 & 10 & 2.1 \\
\hline Biological science & 119 & 8.5 & 36 & 7.7 \\
\hline Chemistry & 15 & 1.1 & 13 & 2.8 \\
\hline Communications & 68 & 4.9 & 6 & 1.3 \\
\hline $\begin{array}{l}\text { Computer \& information } \\
\text { sciences }\end{array}$ & 45 & 3.2 & 42 & 9.0 \\
\hline Computer technology & 25 & 1.8 & 29 & 6.2 \\
\hline Economics & 15 & 1.1 & 13 & 2.8 \\
\hline Education & 123 & 8.8 & 11 & 2.3 \\
\hline Engineering & 29 & 2.1 & 51 & 10.9 \\
\hline Foreign languages & 19 & 1.4 & 5 & 1.1 \\
\hline Health \& medical science & 120 & 8.6 & 21 & 4.5 \\
\hline History & 26 & 1.9 & 9 & 1.9 \\
\hline International business & 19 & 1.4 & 9 & 1.9 \\
\hline Journalism & 24 & 1.7 & 5 & 1.1 \\
\hline Law & 36 & 2.6 & 5 & 1.1 \\
\hline $\begin{array}{l}\text { Law enforcement \& } \\
\text { protective services }\end{array}$ & 21 & 1.5 & 4 & 0.9 \\
\hline Literature & 34 & 2.4 & 5 & 1.1 \\
\hline Management & 57 & 4.1 & 39 & 8.3 \\
\hline Marketing & 44 & 3.1 & 23 & 4.9 \\
\hline Mathematics & 23 & 1.6 & 10 & 2.1 \\
\hline Medical technology & 26 & 1.9 & 4 & 0.9 \\
\hline Performance $\&$ fine arts & 30 & 2.1 & 8 & 1.7 \\
\hline Political science & 33 & 2.4 & 22 & 4.7 \\
\hline Psychology & 149 & 10.6 & 28 & 6.0 \\
\hline Social work & 25 & 1.8 & 0 & 0.0 \\
\hline Sociology & 35 & 2.5 & 7 & 1.5 \\
\hline Other humanities \& liberal arts & 88 & 6.3 & 14 & 3.0 \\
\hline Other social sciences & 24 & 1.7 & 6 & 1.3 \\
\hline
\end{tabular}

employed adults, $50 \%$ women and $50 \%$ men who averaged age 35 years, a mean of 9 years of experience in their respective occupations, and reported working a mean of 41 hrs per week (Donnay et al., 2005). The GRS is reported to have 30\% non-Whites in the sample and to represent more than 370 different occupations (Donnay et al., 2005).

The six 2005 GOTs were broadened to include new items but remain essentially the same (Donnay et al., 2005). They were constructed based on homogeneous 
item content. The internal consistency initial estimates reveal alphas above .90 (Donnay et al., 2005).

The 2005 BISs include 30 homogenous content scales. Of these 30 scales, 10 of the scales are new and 20 scales were revised and updated (Donnay et al., 2005). (Note: Four of the 1994 BISs were dropped, and one scale, Nature, was combined with Agriculture.) In general, the number and range of items per scale was reduced from 5 to 21 items per BIS in 1994 to 6 to 12 items per BIS in the 2005 BISs (Donnay et al., 2005). The median Cronbach's alpha of the 2005 BISs was reported by Donnay et al. (2005) as .87.

The five PSSs are represented as bipolar continua on which each individual falls. The PSSs include Work Style, Learning Environment, Leadership Style, Risk Taking/Adventure, and Teamwork scales with internal consistency estimates reported between .82 and .87 (Donnay et al., 2005). The revised Risk Taking scale was broadened beyond physical risk taking to include financial risk taking and emotional risk taking (Donnay et al., 2005). The Teamwork scale is the new PSS, and it measures to what extent the individual likes to solve problems or tasks independently or as a member of a group.

Major differences between the 1994 and 2005 SII scales include the expansion of the BISs from 25 to 30 scales and the inclusion of another PSS (the Team Orientation scale). As mentioned previously, these changes allow for the expression of new career options that have become available in the workforce in the past decade. Another important change in the 2005 SII was the expansion of the 3-point item response (choice of like, neutral, dislike) to a 5-point item response (choice of strongly like, like, indifferent, dislike, and strongly dislike). This change permits the participant to express more extreme likes and dislikes. Also, preliminary data suggest that this wider range of response options increases the sensitivity of the SII, thus increasing the reliability of the instrument (Donnay et al., 2005). For more reliability and validity information on the 2005 SII, see Donnay et al. (2005).

\section{RESULTS}

\section{Preliminary Analyses}

For the discriminant analyses, the data set of 1,403 women was examined, and then the data set of 469 males was used for validity generalization purposes. Hence, the analyses were run on women, and the sample of men was used for crossvalidation. This approach was followed because the sample size for women was substantially larger and thus could be expected to provide more stable discriminant function weights. This meant that multivariate models for the data were generated for the women, and then the fit of those models to the data on men was examined. In the female sample, there were 31 majors as shown by Table 2 . 
Descriptive statistics were computed for each of the college majors by gender to ensure that the groups were of substantial size for use in later analyses. Majors with $n$ 's smaller than 16 were excluded from further analysis. Originally, there were 75 different majors. After eliminating 44 groups for women and men due to small sample sizes, there were 31 majors for analysis. See Table 2 for a list of the majors and sample sizes of those groups used in the current study. It was decided that excluding majors with small n's was a better strategy in analyzing these data than grouping similar majors together. This decision was reached as a result of two lines of reasoning. First, the research question being addressed in the current study was "how well do these scales discriminate among college majors?" The research question addressed in cluster analysis would be "How well do these scales combine college majors?" which was different than the issue addressed in the current study. Second, the purpose of the current study was to look at how well the 41 content scales of the SII separate college majors, and that conceptually these 41 different scales should be able to do so with great specificity (Ralston et al., 2004). By clustering majors together, we would lose our ability to look at the instrument with greater precision.

Hypothesis 1: Adding the BISs Would Significantly Improve the Correct Classification of Majors for the Female Sample

The first hypothesis was the prediction that the addition of the BISs to the PSSs and the GOTs would yield a significantly higher percentage of correct classifications of the 31 majors for the women than either the PSSs alone or the PSSs and GOTs combined. To test this hypothesis, three discriminant analyses were performed using SPSS 10 for Windows. Three models identified in Table 3 were compared: Model 0 (the PSSs alone), Model 1 (the PSSs plus the GOTs), or Model 2 (the PSSs plus the GOTs plus the BISs). In the first discriminant analysis, the PSSs were entered; in the second analysis, the GOTs were added as predictors; and in the third analysis, the BISs were added as predictors. The criterion variable in each of the three discriminant analyses was major with 31 categories as shown by Table 2 . Also, for each analysis, a priori expectations were set as all groups equal to balance out the effects of different numbers in each major. For 31 majors, assuming equal subgroup sizes, the chance hit rate was $1 / 31$ or $3.2 \%$.

In essence, the primary analyses were designed to compare which model (Model 0 [PSSs alone] vs. Model 1 [PSSs plus GOTs] vs. Model 2 [PSSs plus GOTs plus BISs]) would be more accurate in classifying the 31 majors. Table 3 presents the original hit rates for all three models and the hit rates when the jackknife procedure is used. ${ }^{1}$ The jackknife procedure generates a new hit rate by rerunning the analyses multiple times by removing a case and then replacing it. This procedure provides a cross-validated estimate of the model parameters; it is an attempt to correct for inflated hit rates due to overweighting sample-specific error (Efron, 1983; Lachenbruch, 1967). 


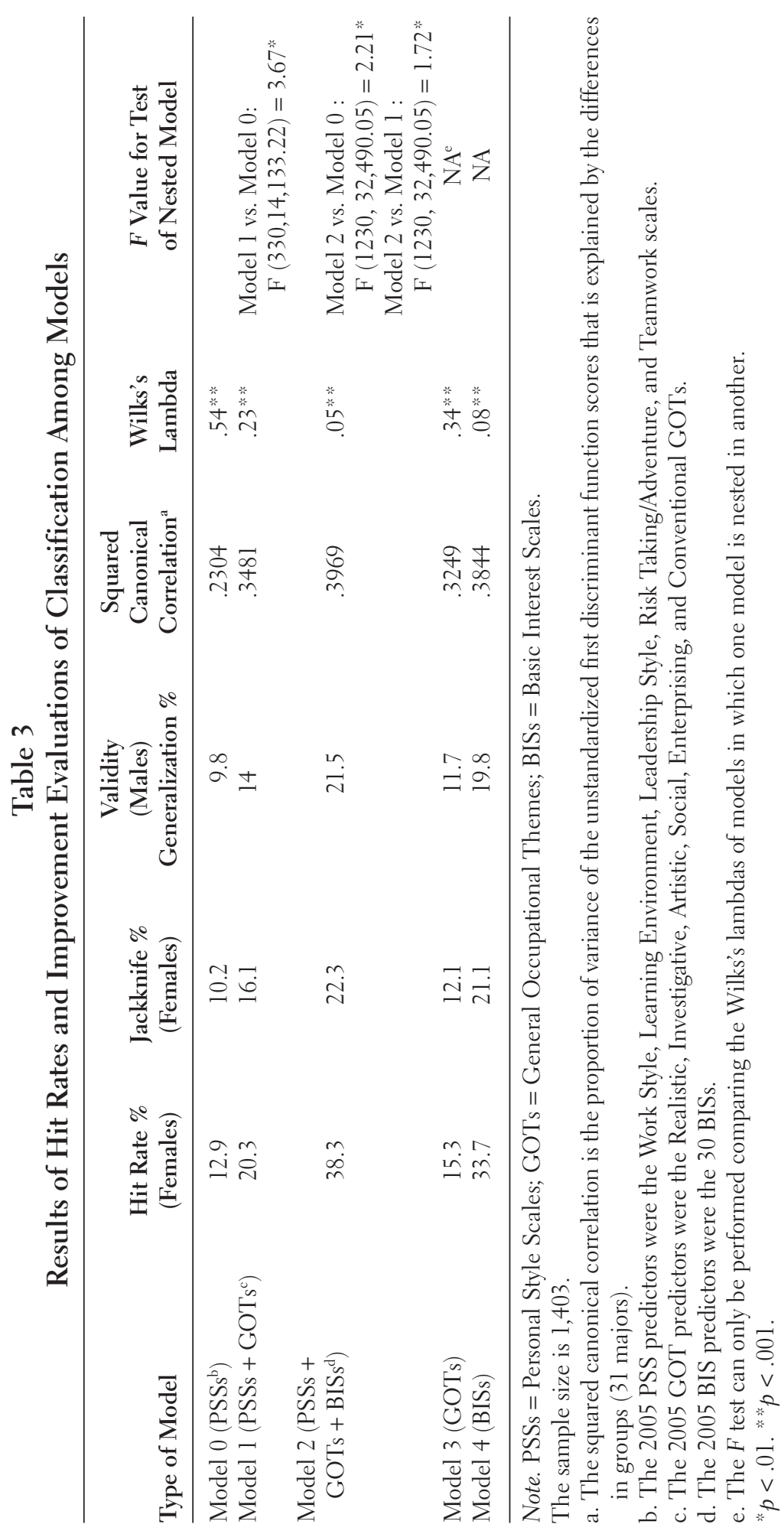


To gain an estimate of effect sizes across the models, Table 3 also presents the squared canonical correlations for the first function in each of the models. The squared canonical correlation for the first function is the proportion of variance of the unstandardized first discriminant function scores that is explained by the differences in groups ( 31 majors). ${ }^{2}$ It is analogous to the $\eta^{2}$ in a one-way ANOVA (see Cohen, Cohen, West, \& Aiken, 2003, p. 319). As shown in Table 3, the effect sizes ranged from 23\% in Model 0 to $40 \%$ in Model 2.

Also shown in Table 3 are the Wilks's lambdas and the $F$ values for the comparison of the three models in terms of the significant reduction in the Wilks's lambda. This F test (developed by Frane, personal communication, 1977) is presented in Tabachnick and Fidell (2001) to evaluate the significance of the decrease in the Wilks's lambda for sequential discriminant analyses. This $F$ test compares nested models (e.g., PSSs alone compared to PSSs plus GOTs). Of interest in this article is the comparison of Models 0 (PSSs), 1 (PSSs plus GOTs), and 2 (PSSs plus GOTs plus BISs).

The first hypothesis was supported. As shown by Table 3, the addition of the GOTs increased the hit rate from 12.9\% with the PSSs alone (Model 0) to $20.3 \%$ when the GOTs were added (Model 1) resulting in a significant increase as shown by the $F$ test $(p<.01)$. Likewise, adding the BIS increased the hit rate from $20.3 \%$ (Model 1) to $38.3 \%$ (Model 2) resulting in a significant increase as shown by the $F$ test $(p<.01)$.

The conservative jackknife procedure yielded lower hit rates as expected; however, the same pattern of results emerged; that is, when the GOTs were added to the PSSs, the hit rate jumped from $10.2 \%$ to $16.1 \%$. Likewise, when the BISs were added, the hit rate jumped from $16.1 \%$ to $22.3 \%$.

Hypothesis 2: BISs Alone Would Correctly Classify Significantly More College Majors for the Female Sample

For the second hypotheses, we expected the BISs alone as a predictor set would yield the highest correct classification among the 31 majors for the women than either the PSSs alone as a predictor set or the GOTs as a predictor set. Moreover, we expected the GOTs alone would be better at differentiating majors than the PSSs alone. Finally, we expected that all three predictor sets alone would discriminate among the college majors better than chance (3.2\%). Two additional discriminant analyses were run to compare Model 0 (PSSs alone) with two other models, namely the GOTs alone (Model 3) and the BISs alone (Model 4). In both discriminant analyses, the criterion variable was major with 31 categories (see Table 2). The predictors were either the six GOTs or the 30 BISs. The original hit rate for these two additional models, the hit rate when implementing the jackknife procedure, the squared canonical correlations, and the Wilks's lambdas are presented in Table 3. Given that Models 3 and 4 are not nested, the $F$ test could not be conducted on these models.

As can be seen by Table 3, the hypothesis was supported. The GOTs alone correctly classified $15.5 \%$, which was slightly higher than the $12.9 \%$ hit rate of 


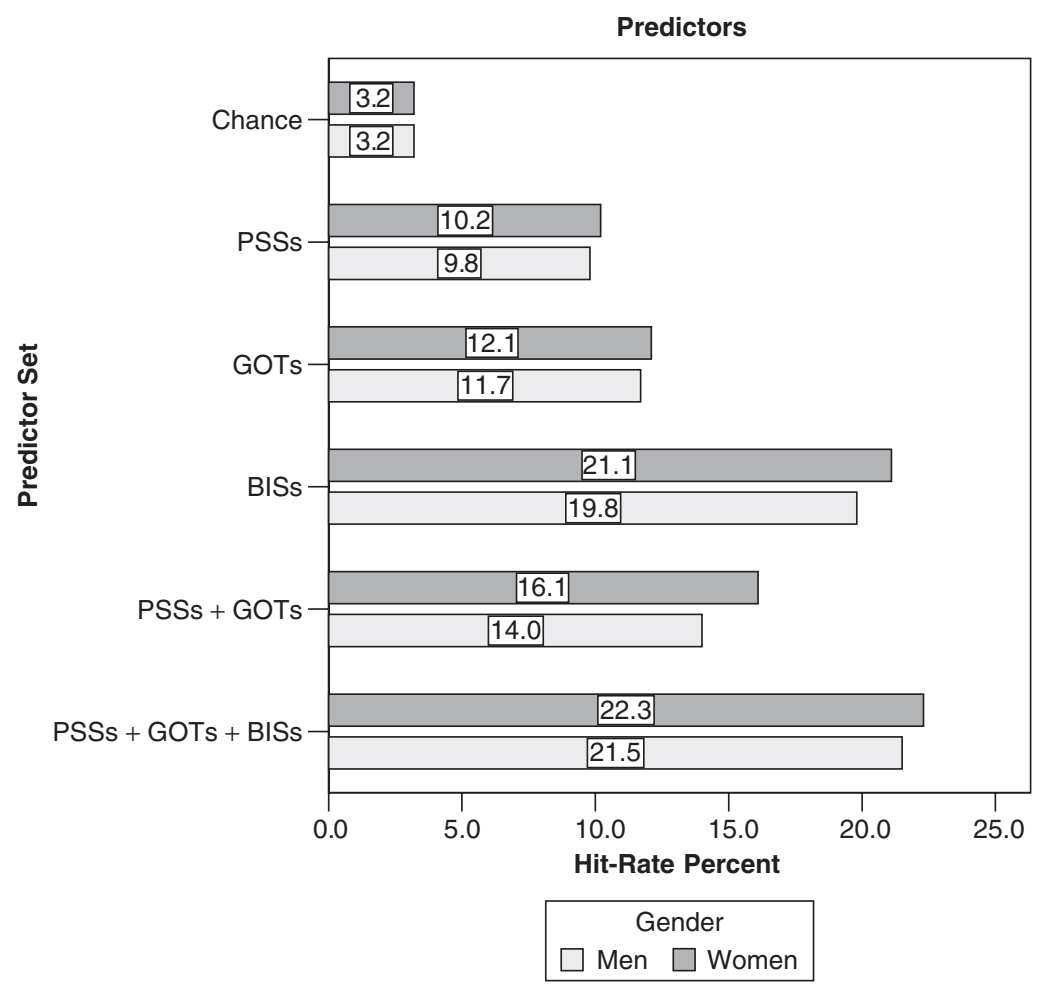

Figure 1. Summary of Discriminant Analyses Hit Rates for Women and Men for the Sets of Predictors.

Note. PSSs = Personal Style Scales; GOTs = General Occupation Scales; BISs = Basic Interest Scales .

the PSSs alone. Also, the BISs alone accurately classified $33.7 \%$ of the 31 majors compared to either the PSSs alone or the GOTs alone.

The jackknife procedure for each model yielded lower, but similar, rankings among the three models with the BISs alone showing a 21.1\% correct classification followed by the GOTs with $12.1 \%$ correct classification followed by the PSSs with $10.2 \%$ correct classification. As expected, the BISs in this sample of women were the most useful in differentiating among college majors.

Hypothesis 3: Validity Generalization to the Male Sample

To validate the results obtained for women, the discriminant analyses models generated for the female data set were examined as to how they generalized to the sample of men. The hit rates for Models 0 through 4 for the male sample are produced as part of the output for the discriminant analyses already presented and are shown in Table 3 .

The same pattern of findings for the women emerged for the men as shown by Table 3 and illustrated in Figure 1. First, as expected, the addition of the GOTs 
increased the accurate classification from $10.2 \%$ with the PSSs alone to $14 \%$ with the PSSs plus the GOTs. The incremental addition of the BISs boosted the hit rate to $21.5 \%$. Second, the GOTs alone yielded a higher hit rate than the PSSs alone (11.7\% vs. $9.8 \%$ ), and the BISs alone yielded the highest hit rate (19.8\%). All three predictor sets were significantly better than the $3 \%$ chance rate-ranging from 3 times better (the PSSs) to more than 6 times better (the BISs).

\section{Additional Univariate Analyses}

To provide individual information about the predictive utility of the $30 \mathrm{BISs}$ in differentiating among the 31 majors, 30 univariate ANOVAs were conducted. College major was the independent variable, and each BIS was the dependent variable. The 31 groups of college majors were treated as the independent variable with 31 levels. The $F$ values and Wilks's lambdas provided the ratio of withingroups sum of squares to the total sum of squares. Wilks's lambda is subtracted from 1 as an indicator of the proportion of variance in college-major group membership that is explained by the particular BIS. For example, the Science BIS explained $21 \%$ of the variance in college major. Thus, smaller Wilks's values here occurred as a result of predictor sets contributing more to group separation.

As can be seen in Table 4, 27 of the BIS ANOVAs were statistically significant at the $p<.001$ level. The only three exceptions to this were for the Athletics BIS, the Religion and Spirituality BIS, and the Culinary Arts BIS. The BIS Athletics was significant at the $p=.01$ level, whereas the BIS Religion and Spirituality and the BIS Culinary Arts were significant at $p=.12$. Wilks's lambdas across the BISs ranged from .78 (BIS Medical Science) to .97 (BIS Culinary Arts and BIS Religion and Spirituality), which means that the scales individually accounted for $3 \%$ to $22 \%$ of the variance explained by college major separation.

\section{DISCUSSION}

Figure 1 summarizes the discriminant results, which were very similar for men and women. All sets of scales substantially improved on chance in their predictive ability. The hypotheses about which set of scales would add most to prediction of college major were confirmed. The PSSs showed hit rates 3 times greater than chance; the GOTs had hit rates 4 times greater than chance; and the BISs had hit rates more than 6 times chance. When the specific BISs were added to the PSSs and GOTs, they increased the hit rates by about 6 to 8 percentage points.

It was expected that the models generated for the women would probably not fit as well for the men. However, it was interesting that the hit rates for the male validity generalization sample were as high as they were. This finding suggests that the models generated for the women were fitting well for the smaller sample of men. Thus, the results are clear for women and men in showing the incremental validity of the BISs in these multivariate models. This suggested that, as 
Table 4

Univariate Analyses of Variances Results for the Basic Interest Scales (BIS) for the Women $(N=1403)$

\begin{tabular}{lcc}
\hline Dependent Variable & Wilks's Lambda & $\boldsymbol{F}$ \\
\hline Mechanics \& construction & .90 & 5.24 \\
Computer hardware \& electronics & .85 & 8.23 \\
Military & .93 & 3.42 \\
Protective services & .91 & 4.52 \\
Nature \& agriculture & .95 & 2.56 \\
Athletics & .96 & 1.69 \\
Science & .79 & 12.44 \\
Research & .90 & 4.86 \\
Medical science & .78 & 12.82 \\
Mathematics & .84 & 8.65 \\
Visual arts \& design & .90 & 5.20 \\
Performing arts & .93 & 3.66 \\
Writing \& mass communication & .84 & 8.60 \\
Culinary arts & .97 & 1.31 \\
Counseling \& helping & .88 & 6.09 \\
Teaching \& education & .88 & 6.09 \\
Human resources \& training & .91 & 4.28 \\
Social sciences & .90 & 4.92 \\
Religion \& spirituality & .97 & 1.31 \\
Healthcare services & .82 & 9.95 \\
Marketing \& advertising & .84 & 8.91 \\
Sales & .88 & 6.48 \\
Management & .89 & 5.44 \\
Entrepreneurship & .88 & 6.23 \\
Politics \& public speaking & .87 & 6.94 \\
Law & .90 & 5.13 \\
Office management & .88 & 6.38 \\
Taxes \& accounting & .82 & 10.33 \\
Programming \& information services & .84 & 8.78 \\
Finance \& investing & .84 & 9.07 \\
\hline Note All vales wre & & \\
\hline
\end{tabular}

Note. All values were significant at $p<.001$ with the following exceptions: BIS Athletics $(p=.01)$; BIS Religion and spirituality $(p=.12)$; BIS Culinary arts $(p=.12)$.

the scales' specificity to unique career interests increased, so did their ability to differentiate among college majors.

It is interesting to note that when the results for each of the sets of scales alone were compared to the results for the sets of scales combined, the hit rates for the analyses where the BISs were included were similar. In other words, the hit rate for the $30 \mathrm{BISs}$ alone was $33.7 \%$, whereas the hit rate for the BISs with the PSSs and GOTs was $38.3 \%$. The PSSs alone had a hit rate of $12.9 \%$, and the GOTs had a hit rate of $15.5 \%$. Clearly, it appears that the BISs contributed almost as much as the three sets of scales combined. The same cannot be said for the PSSs or the GOTs. 
Because this is the first article to provide concurrent criterion validity on the 2005 SII, the closest comparable findings are validity studies using the 1994 SII to predict occupational membership (Donnay \& Borgen, 1996; Olsen, 1996). They used the 1994 SII GRS; Donnay and Borgen examined the total sample while Olsen examined men and women separately. In women and men separately and the total sample, our findings corroborate these findings; that is, the PSSs, GOTs, and BISs combined yielded the strongest hit rate of $25 \%$ for the total sample and for the female and male samples separately (Donnay \& Borgen, 1996; Olsen, 1996). Moreover, in both studies, the BISs alone yielded a higher hit rate than either the PSSs alone or the GOTs alone.

Gender comparisons. In the current study, we found support for the ability of the 2005 SII scales to correctly classify college majors for women and men when using models generated for women. Our findings replicate Olsen's (1996) findings with the 1994 GRS. Olsen (1996) found that there were minimal differences between men and women. Olsen concluded that the SII scales predict occupational group membership equally well for women and men. These finding imply that the interests of college majors between genders are probably more similar than different from one another.

\section{Univariate Results}

For the 2005 SII, 27 of the 30 BISs were able to separate college majors at the $p<.001$ level. The only three scales that were not as useful in differentiating between college majors were the Athletics BIS, the Religion and Spirituality BIS, and the Culinary Arts BIS. Our results are consistent with Olsen (1996) and Donnay and Borgen (1996) who found that all 25 of the 1994 BISs separated occupational groups $(p<.001)$. One small difference between the current study and the other two studies was the findings for the three nonsignificant BISs in the 2005 sample. One probable reason for the lack of significant findings was that there were no religion or culinary arts majors in the current study's sample.

An illustrative example. The utility of the BISs predictive capability lies in differentiating within a Holland code (A Holland code is a three-letter code describing an individual's most salient vocational interests in terms of the RIASEC. For example, an individual with the code ASR has endorsed more interest and greater person-environment fit with the Artistic [A], Social [S], and Realistic [R] domains). To illustrate, two majors (Social Work and Education) that are high on the Social GOT but differentiated on the relevant BIS are displayed graphically. Figures 2 and 3 present the GOT means for Social Work majors and Education majors. For these women, the Social GOT was dominant. A counselor examining only the GOTs would not find much distinction between these two majors as shown by Figures 2 and 3 .

However, when the counselor includes the BIS profiles for these two majors, differentiation is immediately apparent as visually displayed in Figures 4 and 5. The two highest BIS means were reversed for these majors. For the Social Work 


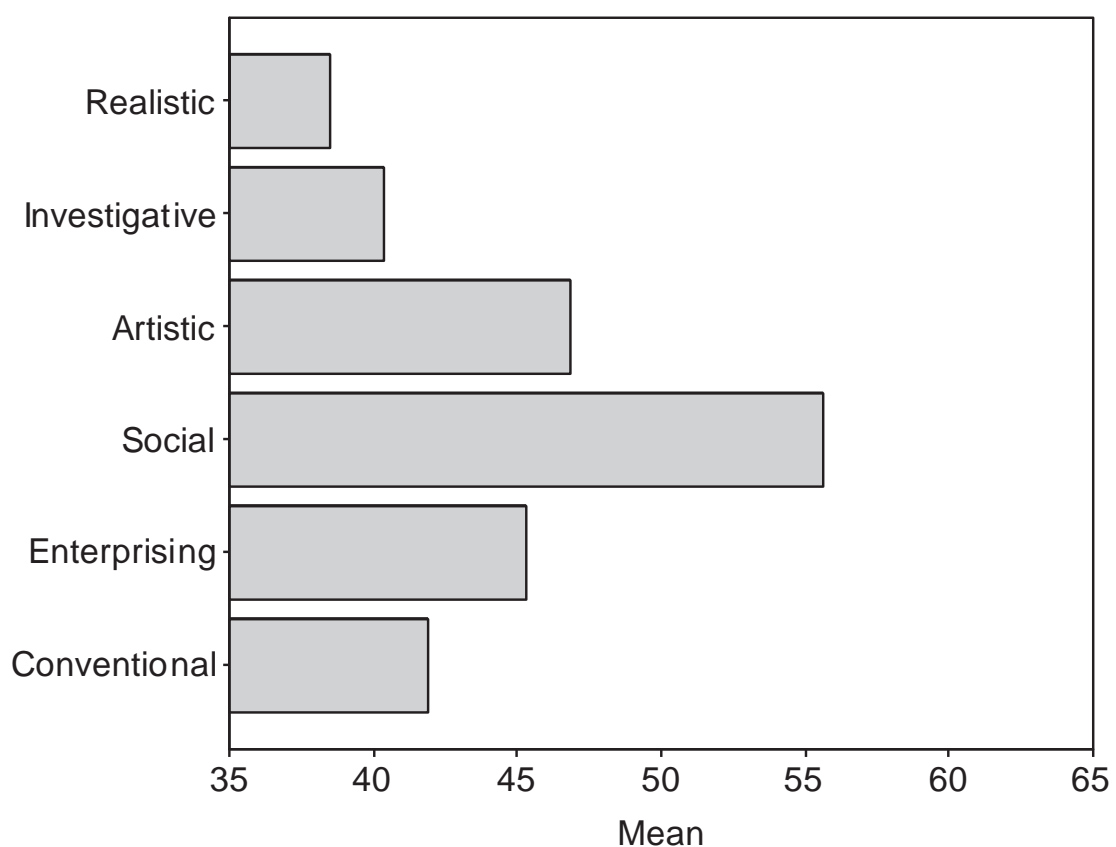

Figure 2. General Occupational Themes of the Social Work Majors.

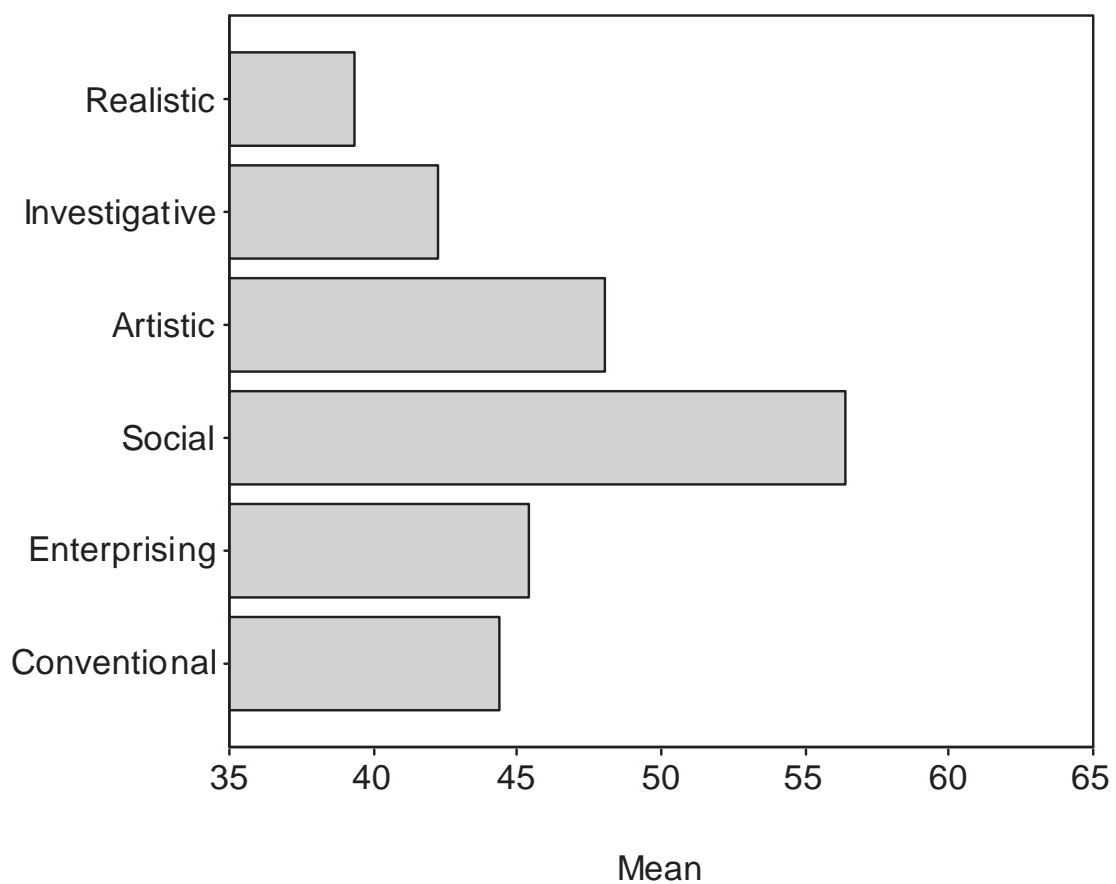

Figure 3. General Occupational Themes of the Education Majors. 


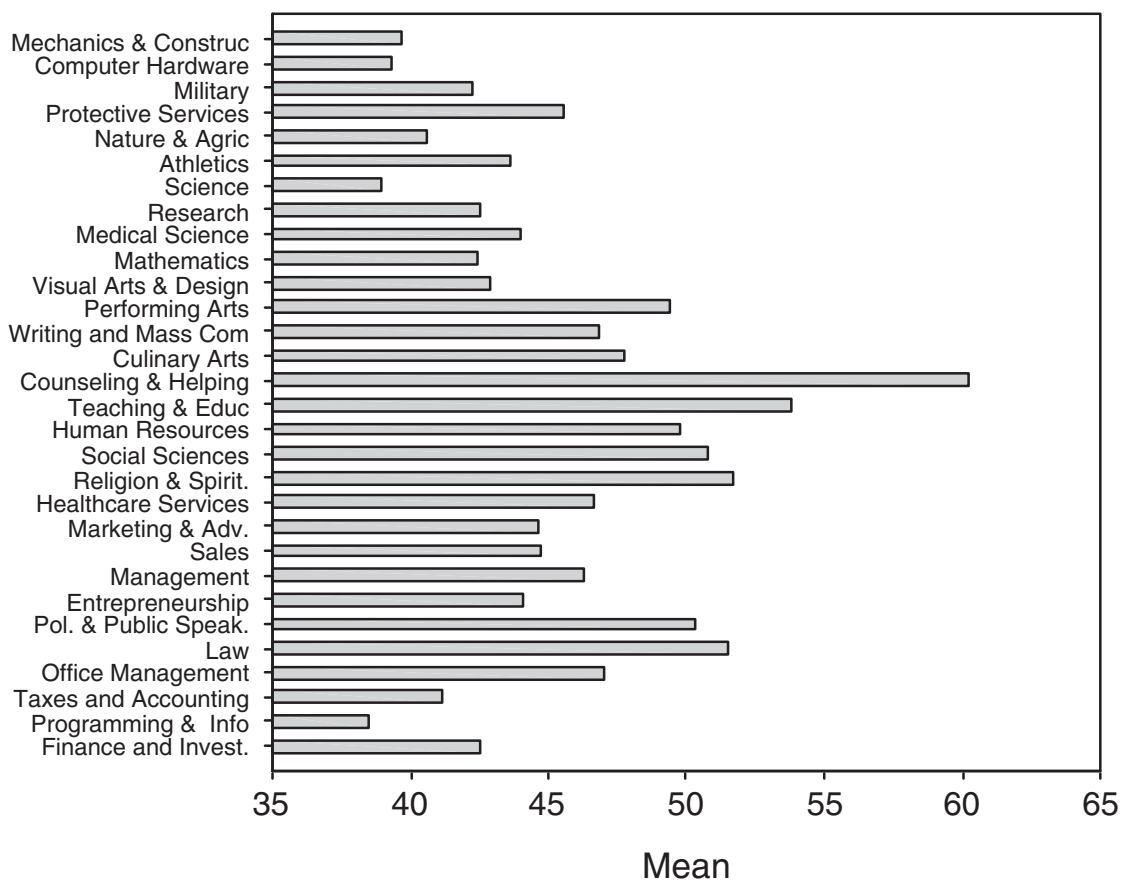

Figure 4. Basic Interest Scales of the Social Work Majors.

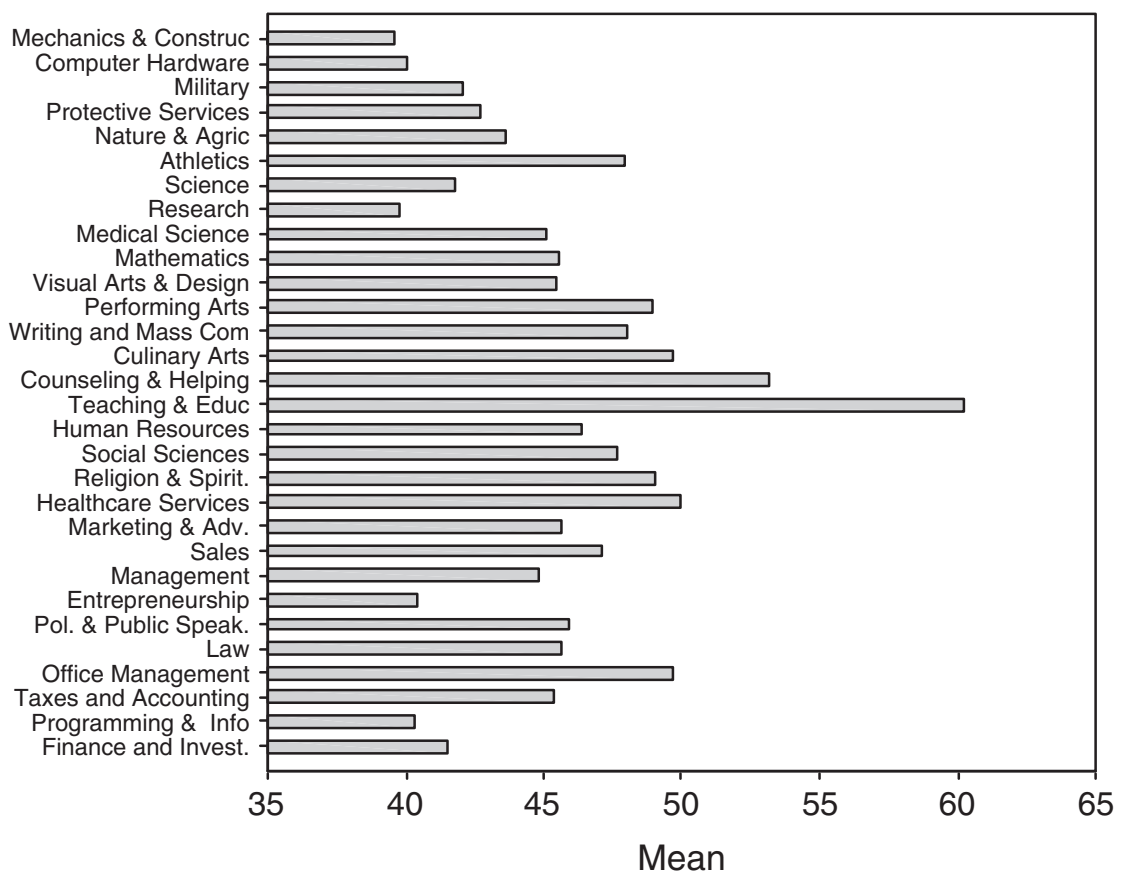

Figure 5. Basic Interest Scales of the Education Majors. 
majors, the Counseling and Helping BIS mean was most dominant (followed by the Teaching and Education BIS). In contrast, for the Education majors, the highest mean was for the Teaching and Education BIS (followed by the next highest mean for the Counseling and Helping BIS).

\section{Limitations}

There were several limitations of the current study. The current study could have benefited from a greater breadth of majors themselves. In our sample, there were many Social majors, Artistic majors, and Investigative majors. However, there were fewer Conventional and Enterprising majors. In particular, there were very few Realistic majors. Therefore, the findings were limited in describing the separation of Realistic majors. In addition, even though we had a sample of 469 men, it would have been ideal to have an even larger sample.

\section{Future Directions}

The current study was one of the first to examine the 2005 SII. Although the current study has begun the process of establishing the concurrent validity of the 2005 SII scales in differentiating between college majors, more work on the validity of the revised instrument is needed. Other work is needed to replicate these findings and further explore the utility of this instrument. Furthermore, the lack of gender differences in hit rates (major classification) should also be verified. Finally, the current study showed that college majors could be differentiated from one another using the SII scales. This finding should be examined in regards to other college samples and to other populations, such as working adults.

\section{Implications}

Theoretical and practical implications of the current study's results were considered. Regarding theoretical implications, the ability of the BISs to draw out specific related majors showed that the BISs were performing in line with conceptual expectations. Overall, the 2005 SII scales appeared to form a valid measure of vocational interests of college students. Consequently, these scales were reflecting the structure of interests and majors that were postulated. Evidence for this was represented in that all three of the current study's hypotheses were generally supported.

Another implication of the current study was that the 2005 SII's use with the college population should be encouraged. The current study's major finding was that there was support for the valid use of this instrument with a collegiate population. Furthermore, the 2005 SII was able to separate the interests of female college majors, and this finding was generalizable to male college majors. Specifically, the PSSs, GOTs, and BISs had utility in correctly classifying the interests of college majors, and the BISs were especially powerful in this regard. Although replication of these findings is necessary, the current study laid the groundwork for future validity work and provided evidence of the utility of the 2005 SII. Therefore, because 
this instrument appeared to be valid, it has much utility in helping individuals to gain valuable information and insight regarding vocational interests.

Along this line of reasoning, there were other practical implications. Based on the current study's findings regarding the ability of the sets of SII scales to classify college majors, the following clinical recommendations are suggested. If a client is struggling to find an appropriate career, these findings provide support for the use of the 2005 SII in helping the client narrow down the list of potential majors. In career counseling, the GOTs should be used by the counselor to create a general framework of the client's career interests, and the PSSs should add to fleshing out that general framework. However, the career counselor should pay most attention to a client's scores on the BISs to guide the client toward potential major choices. For example, a client may have strong artistic interests as shown by a high score on the Artistic GOT. However, there are many different career directions within this general interest group. The client could have a high score on the Writing and Mass Communication BIS and a lower score on the Culinary Arts BIS, which would have implications for pursuing different artistic careers. Assuming that the client finds this profile to be accurate, in this case, the career counselor could help guide the client toward exploring careers that involve writing rather than those that focus on working with food. Hence, the specificity of the BISs can add to how a career counselor conceptualizes an individual's career interests, as well as informing the client about specific interest areas to pursue or avoid in exploring major and career choices. The special utility of the BISs for guiding the selection of college major was also demonstrated by the Ralston et al. (2004) study of the 1994 SII.

\section{CONCLUSION}

The current study showed that the 2005 SII PSSs, GOTs, and BISs were useful overall in separating college majors for women and men. Furthermore, the greater specificity of the BISs in interest measurement suggested that the BISs be utilized in providing a client with more specific feedback in career counseling. In conclusion, the 2005 SII appeared to have concurrent validity in differentiating between the interests of college majors.

\section{NOTES}

1. Detailed discriminant analyses results are available from the first author.

2. Counseling psychologists may be used to seeing 1 -Wilks's lambda as the reported effect size in discriminant analyses that is accurate when the number of groups being classified is two. This is because when there are only two groups, the canonical correlation in a discriminant analysis is equal to the square-root of 1 - lambda. However, when the number of groups being classified is greater than two, then the interpretation of 1 - Wilks's lambda is unclear; rather the squared canonical correlation is the appropriate effect size and is the proportion of variance of the discriminant function scores that is explained by the differences in groups (six major families in the current study; D. Bonett, personal communication, May 30, 2005). 


\section{REFERENCES}

American Psychological Association. (2002). Ethical principles of psychologists and code of conduct. American Psychologist, 57, 1060-1073 Available at www.apa.org/ethics/code2002.html

Barnes, J. A., \& Herr, E. L. (1998). The effects of interventions on career progress. Journal of Career Development, 24, 179-193.

Betz, N. E., \& Borgen, F. H. (2000). The future of career assessment: Integrating vocational interests with self-efficacy and personal styles. Journal of Career Assessment, 8, 329-338.

Borgen, F. H., \& Harmon, L. W. (1996). Linking interest assessment and personality theory: An example of convergence between practice and theory. In M. L. Savickas \& W. B. Walsh (Eds.), Handbook of career counseling theory and practice (pp. 251-266). Palo Alto, CA: Davies-Black.

Brown, S. D., Lent, R. W., \& Gore, P. A. (2000). Self-rated abilities and self-efficacy beliefs: Are they empirically distinct? Journal of Career Assessment, 8, 223-235.

Buboltz, W. C., Thomas, A., \& Johnson, P. (2001). The relationship between MBTI and Strong: Implications for conjunctive use in counseling. In F. Columbus (Ed.), Advances in psychology research (Vol. 5, pp. 109-139). Hauppauge, NY: Nova Science Publishers.

Chartrand, J. M., Borgen, F. H., Betz, N. E., \& Donnay, D. A. C. (2002). Using the Strong Interest Inventory and the Skills Confidence Inventory to explain career goals. Journal of Career Assessment, 10, 169-189.

Cohen, J., Cohen, P., West, S. G., \& Aiken, L. S. (2003). Applied multiple regression/correlation analysis for the behavioral sciences (3rd ed.). Mahwah, NJ: Lawrence Erlbaum.

Davison Aviles, R. M., \& Spokane, A. R. (1999). The vocational interests of Hispanic, African American, and White middle school students. Measurement and Evaluation in Counseling and Development, 32, 138-148.

Donnay, D. A. C., \& Borgen, F. H. (1996). Validity, structure, and content of the 1994 Strong Interest Inventory. Journal of Counseling Psychology, 43, 275-291.

Donnay, D. A. C., Morris, M. L., Schaubhut, N. A., \& Thompson, R. C. (2005). Strong Interest Inventory manual: Research, development, and strategies for interpretation. Mountain View, CA: CPP Inc.

Efron, B. (1983). Estimating the error rate of a prediction rule: Improvement on cross-validation. Journal of the American Statistical Association, 78, 316-331.

Fouad, N. A. (2002). Cross-cultural differences in vocational interests: Between-group differences on the Strong Interest Inventory. Journal of Counseling Psychology, 49, 282-289.

Fouad, N. A., Harmon, L. W., \& Borgen, F. H. (1997). Structure of interests in employed male and female members of US racial-ethnic minority and nonminority groups. Journal of Counseling Psychology, 44, 339-345.

Gasser, C. E., Larson, L. M., \& Borgen, F. H. (2004). Educational aspirations of college students: Contributions of personality and interests. Journal of Career Assessment, 12, 347-365.

Hansen, J. C. (2005). Assessment of interests. In S. D. Brown \& R. W. Lent (Eds.), Career development and counseling: Putting theory and research to work (pp. 281-304). New York: John Wiley.

Hansen, J. C., \& Campbell, D. C. (1985). Manual for the Strong Interest Inventory (4th ed.). Palo Alto, CA: Consulting Psychologists Press.

Harmon, L. W., \& Borgen, F. H. (1995). Advances in career assessment and the 1994 Strong Interest Inventory. Journal of Career Assessment, 3, 347-372.

Harmon, L. W., Hansen, J. C., Borgen, F. H., \& Hammer, A. L. (1994). Strong Interest Inventory applications and technical guide. Palo Alto, CA: Consulting Psychologists Press.

Holland, J. L. (1997). Making vocational choices: A theory of vocational personalities and work environments (3rd ed.). Odessa, FL: Psychological Assessment Resources.

Jackson, C. C. (2002). Careers in crisis: The relationship between person-environment fit and job satisfaction (Doctoral dissertation, Florida Atlantic University, 2002). Dissertation Abstracts International, 62, 4828. 
Kahn, J. H., Nauta, M. M., Gailbreath, R. D., Tipps, J., \& Chartrand, J. M. (2002). The utility of career and personality assessment in predicting academic progress. Journal of Career Assessment, $10,3-23$.

Kaufman, A. S., \& McLean, J. E. (1998). An investigation into the relationship between interests and intelligence. Journal of Clinical Psychology, 54, 279-295.

Lachenbruch, P. A. (1967). An almost unbiased method of obtaining confidence intervals for the probability of misclassification in discriminant analysis. Biometrics, 23, 639-645.

Larkin, J. E., Harvey, A., \& Bechtel, K. M. (2002). Facilitating students' career development in psychology courses: A portfolio project. Teaching of Psychology, 29, 207-210.

Larson, L. M., \& Borgen, F. H. (2002). Convergence of vocational interests and personality and personality: Examples in an adolescent gifted sample. Journal of Vocational Behavior, 60, 91-112.

Larson, L. M., Rottinghaus, P. J., \& Borgen, F. H. (2002). Meta-analysis of Big Six Interests and Big Five Personality Factors. Journal of Vocational Behavior, 61, 217-239.

Lattimore, R. R., \& Borgen, F. H. (1999). Validity of the 1994 Strong Interest Inventory with racial and ethnic groups in the United States. Journal of Counseling Psychology, 46, 185-195.

Low, K. S. D., Yoon, M., Roberts, B. W., \& Rounds, J. (2005). The stability of vocational interests from early adolescence to middle adulthood: A quantitative review of longitudinal studies. Psychological Bulletin, 131, 713-737.

Luzzo, D. A., \& Day, M. A. (1999). Effects of Strong Interest Inventory feedback on career decisionmaking self-efficacy and social cognitive career beliefs. Journal of Career Assessment, 7, 1-17.

Olsen, L. L. (1996). Concurrent validity of the 1994 "Strong Interest Inventory": A comparison of criterion groups by gender (Doctoral dissertation, Iowa State University, 1996). Dissertation Abstracts International, 57, 2878.

Prince, J. P. (1998). Interpreting the Strong Interest Inventory: A case study. Career Development Quarterly, 46, 339-346.

Ralston, C. A., Borgen, F. H., Rottinghaus, P. J., \& Donnay, D. A. C. (2004). Specificity in interest measurement: Basic Interest Scales and major field of study. Journal of Vocational Behavior, 65, 203-216.

Ralston, C. A., Miller, P. J., Zakalik, R. A., Rottinghaus, P. J., \& Betz, N. E. (2003, August). Specificity and synergy of interests and confidence for college career behaviors. Poster presented at the annual meeting of the American Psychological Association, Toronto, Canada.

Rottinghaus, P. J., Lindley, L. D., Green, M. A., \& Borgen, F. H. (2002). Educational aspirations: The contribution of personality, self-efficacy, and interests. Journal of Vocational Behavior, 61, 1-19.

Savickas, M. L. (1998). Interpreting interest inventories: A case example. Career Development Quarterly, 46, 307-310.

Staggs, G. D., Larson, L. M., \& Borgen, F. H. (in press). Convergence of interests and personality: Meta-analyses of the Multidimensional Personality Questionnaire and the Strong Interest Inventory. Journal of Career Assessment.

Staggs, G. D., Larson, L. M., \& Borgen, F. H. (2004). Convergence of interests and personality: Metaanalyses of the Strong Interest Inventory and the Multidimensional Personality Questionnaire. Manuscript submitted for publication.

Swanson, J. L. (1992). Generating hypotheses from Rachel's Strong profile. Career Development Quarterly, 41, 31-35.

Strong, E. K. (1927). Vocational Interest Test. Educational Record, 8, 107-121.

Swanson, J. L., \& Fouad, N. A. (1999). Career theory and practice: Learning through case studies. Thousand Oaks, CA: Sage.

Tabachnick, B. G., \& Fidell, L. S. (2001). Using multivariate statistics (4th ed.). New York: HarperCollins.

Toman, S. M., \& Savickas, M. L. (1997). Career choice readiness moderates the effects of interest inventory interpretation. Journal of Career Assessment, 5, 275-291. 
Watkins, C. E., Campbell, V. L., \& Nieberding, R. (1994). The practice of vocational assessment by counseling psychologists. Counseling Psychologist, 22, 115-128.

Zao, K. E. (2002). Older volunteers, person-environment fit, and life satisfaction (Doctoral dissertation, University of Wisconsin-Milwaukee, 2002). Dissertation Abstracts International, 62, 5420.

Zytowski, D. G., \& Warman, R. E. (1982). The changing use of tests in counseling. Measurement and Evaluation in Guidance, 15, 147-152. 